\title{
Mitral valve repair for isolated posterior mitral valve leaflet prolapse: The effect of respect and resect techniques on left ventricular function
}

Aniek L. van Wijngaarden, MD, ${ }^{\mathrm{a}}$ Anton Tomšič, MD, ${ }^{\mathrm{b}}$ Bart J. A. Mertens, $\mathrm{PhD},{ }^{\mathrm{c}}$ Federico Fortuni, MD, ${ }^{\mathrm{a}, \mathrm{d}}$ Victoria Delgado, MD, PhD, ${ }^{a}$ Jeroen J. Bax, MD, PhD, ${ }^{a}$ Robert J. M. Klautz, MD, PhD, ${ }^{b}$

Nina Ajmone Marsan, $\mathrm{MD}, \mathrm{PhD},{ }^{a}$ and Meindert Palmen, $\mathrm{MD}, \mathrm{PhD}^{\mathrm{b}}$

\section{ABSTRACT}

Objective: Posterior mitral valve leaflet prolapse repair can be performed by leaflet resection or chordal replacement techniques. The impact of these techniques on left ventricular function remains a topic of debate, considering the presumed better preservation of mitral-ventricular continuity when leaflet resection is avoided. We explored the effect of different posterior mitral valve leaflet repair techniques on postoperative left ventricular function.

Methods: In total, 125 patients were included and divided into 2 groups: leaflet resection $(n=82)$ and isolated chordal replacement $(n=43)$. Standard and advanced echocardiographic assessments were performed preoperatively, directly postoperatively, and at late follow-up. In addition, left ventricular global longitudinal strain was measured and corrected for left ventricular end-diastolic volume to adjust for the significant changes in left ventricular volumes.

Results: At baseline, no significant intergroup difference in left ventricular function was observed measured with the corrected left ventricular global longitudinal strain (resect: $1.76 \% \pm 0.58 \% / 10 \mathrm{~mL}$ vs respect: $1.70 \% \pm 0.57 \% / 10 \mathrm{~mL}, P=.560$ ). Postoperatively, corrected left ventricular global longitudinal strain worsened in both groups but improved significantly during late follow-up, returning to preoperative values (resect: $1.39 \% \pm 0.49 \%$ to $1.71 \% \pm 0.56 \% / 10 \mathrm{~mL}, P<.001$ and respect: $1.30 \% \pm 0.45 \%$ to $1.70 \% \pm 0.54 \% / 10 \mathrm{~mL}, P<.001)$. Mixed model analysis showed no significant effect on the corrected left ventricular global longitudinal strain when comparing the 2 different surgical repair techniques over time $(P=.943)$.

Conclusions: Our study showed that both leaflet resection and chordal replacement repair techniques are effective at preserving postoperative left ventricular function in patients with posterior mitral valve leaflet prolapse and significant regurgitation. (J Thorac Cardiovasc Surg 2022;164:1488-97)

Surgical mitral valve (MV) repair is the standard treatment for MV prolapse. The posterior MV leaflet is involved in the

From the ${ }^{\mathrm{a}}$ Division of Cardiac Imaging, Department of Cardiology, ${ }^{\mathrm{b}}$ Division of Cardiothoracic Surgeons, Department of Cardiothoracic Surgery, and ${ }^{\mathrm{c} D i v i s i o n}$ of Medical Statistics, Department of Biomedical Sciences, Leiden University Medical Center, Leiden, The Netherlands; and ${ }^{\mathrm{d}}$ Division of Cardiology, Department of Molecular Medicine, University of Pavia, Pavia, Italy.

Received for publication Aug 18, 2020; revisions received Jan 28, 2021; accepted for publication Feb 3, 2021; available ahead of print Feb 23, 2021.

Address for reprints: Nina Ajmone Marsan, MD, PhD, Department of Cardiology, Leiden University Medical Center, Albinusdreef 2, 2333 ZA Leiden, The Netherlands (E-mail: n.ajmone@lumc.nl).

0022-5223

Copyright (C) 2021 by The American Association for Thoracic Surgery. Published by Elsevier Inc. This is an open access article under the CC BY license (http:// creativecommons.org/licenses/by/4.0/).

https://doi.org/10.1016/j.jtcvs.2021.02.017

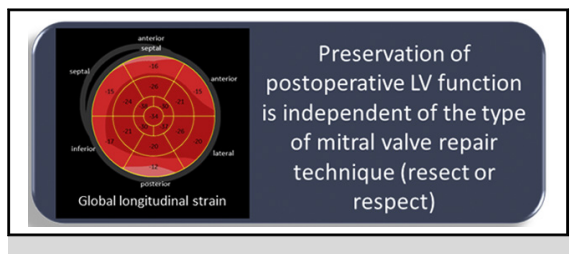

Example of a bull's-eye with LV strain values.

CENTRAL MESSAGE

Leaflet resection and chordal

replacement techniques are

both effective at preserving

postoperative LV function as as-

sessed by GLS corrected for end-

diastolic volume.

\section{PERSPECTIVE}

MV repair techniques are a topic for debate regarding the effect on LV function after surgery. We showed that leaflet resection and chordal replacement are both effective at preserving postoperative LV function. Therefore, the choice of repair technique should be only tailored to reach absence of leaflet prolapse, obtaining enough coaptation, avoidance of MV systolic anterior motion, and residual MR.

See Commentaries on pages 1498,1499 , an 1500.

majority of cases, either in the setting of isolated posterior leaflet or bileaflet prolapse, and different surgical repair techniques have been developed with the goal of correcting any leaflet prolapse and addressing excessive leaflet tissue in height or width and to prevent systolic anterior motion of the MV. ${ }^{1,2}$

Posterior leaflet prolapse has been treated by resection for many years; however, alternative approaches focusing

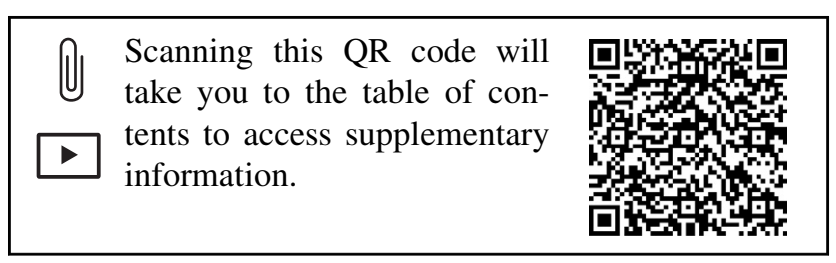




$$
\begin{aligned}
& \text { Abbreviations and Acronyms } \\
& \begin{aligned}
\text { GLS } & =\text { global longitudinal strain } \\
\mathrm{IQR} & =\text { interquartile range } \\
\mathrm{LA} & =\text { left atrial } \\
\mathrm{LV} & =\text { left ventricular } \\
\mathrm{LVEF} & =\text { left ventricular ejection fraction } \\
\mathrm{MR} & =\text { mitral regurgitation } \\
\mathrm{MV} & =\text { mitral valve }
\end{aligned}
\end{aligned}
$$

on preserving leaflet tissue have been implemented. Replacement of native MV chordae with artificial polytetrafluoroethylene sutures was first described by Tirone David for the treatment of anterior MV leaflet prolapse. ${ }^{3}$ Chordal replacement repair techniques for the treatment of posterior leaflet prolapse were later popularized by Perier and colleagues, ${ }^{4}$ providing an alternative to the leaflet resection techniques and possibly better preserving the mitralventricular continuity. Since then, a growing preference for chordal replacement techniques over leaflet resection techniques has been observed, although this technique might not be suited in all cases of MV leaflet prolapse. ${ }^{5-7}$ The suitability and superiority of various repair techniques used to resolve posterior MV leaflet prolapse remain a matter of debate. Recent studies have suggested that chordal replacement techniques are related to superior postrepair left ventricular (LV) performance, arguably, by preserving the valvulo-ventricular continuity. ${ }^{8}$ This could provide an important argument for the use of chordal replacement rather than leaflet resection techniques; however, because important methodological limitations exist, further studies are needed to evaluate the effect of various repair techniques on LV performance.

The aim of this study was to compare the effect of leaflet resection (resect) and isolated chordal replacement (respect) techniques for isolated posterior MV leaflet prolapse on postrepair LV morphology and function. In addition to standard echocardiographic parameters, global longitudinal strain (GLS) was measured as a more sensitive and less load-dependent echocardiographic parameter in depicting changes in LV function.

\section{MATERIALS AND METHODS}

\section{Study Population and Clinical Characteristics}

Patients who underwent MV repair for isolated prolapse of the posterior leaflet with moderate-to-severe or severe mitral regurgitation (MR) at the Leiden University Medical Center (Leiden, The Netherlands) between January 2000 and December 2018 were included. The following exclusion criteria were used (Figure E1): unavailable echocardiogram preoperatively, postoperatively, or late follow-up; GLS measures not feasible; concomitant coronary artery bypass grafting and aortic valve replacement. Patients who underwent concomitant tricuspid annuloplasty or Maze procedure were included. Preoperative demographic and clinical characteristics of patients were collected from the hospital information system (HIX 6.1; ChipSoft BV, Amsterdam, The Netherlands) and the patient electronic record used by the cardiology department (EPD-Vision; Leiden University Medical Center, Leiden, The Netherlands). The following preoperative information was obtained: age, sex, New York Heart Association classification, presence of atrial fibrillation (paroxysmal or permanent), hypertension, diabetes, chronic lung disease, coronary artery disease, renal function, and medication use. The study complies with the Declaration of Helsinki, and this retrospective study was approved by the Institutional Review Board and Medical Ethical Committee, which waived the need of written patient informed consent.

\section{Surgical Technique}

The surgical approach to posterior MV leaflet prolapse has been described. ${ }^{5,7}$ Intraoperatively, the posterior leaflet was assessed for the presence of prolapse, the quality of the subvalvular apparatus, and the excessive leaflet tissue. Early in the study period (before 2008), leaflet resection techniques were predominantly used. In such cases, posterior leaflet prolapse and excessive tissue were addressed by quadrangular resection and leaflet sliding or annular plication. In the presence of more limited prolapse with little excessive tissue, a more limited triangular resection was used. Later in the study period (after 2008), chordal replacement techniques were progressively used. Chordal replacement techniques were used to treat isolated leaflet prolapse or leaflet prolapse with excessive tissue in height. In case of the latter, neochordae were made shorter not only to correct the prolapse but also to lower the height of the posterior leaflet, thereby moving the closure line more posteriorly, as described by Perier and colleagues. ${ }^{4}$ In all cases, the presence of excessive tissue in width resulted in resection of the excess of tissue in width. Particular care was made to avoid excessive tissue resection that could have resulted in excessive shortening of the leaflet free edge, possibly hampering normal leaflet motion. In addition, in all patients except 1 , a semi-rigid ring annuloplasty was performed. All operations were performed by experienced MV surgeons. Intraoperative echocardiography was performed by an experienced cardiologist to analyze the result of valve repair.

\section{Standard Echocardiography}

Standard transthoracic 2-dimensional echocardiography was performed in all patients before surgery (baseline), directly postoperatively (predischarge), and during follow-up using commercially available ultrasound devices (Vivid 5, Vivid 7, and E9; GE-Vingmed, Milwaukee, Wis). Only echocardiograms taken up to 2 years after surgery were used as followup echocardiograms. Later follow-up echocardiograms were discarded to minimize the impact of other events on LV function. The late follow-up timepoint in Tables 1 and E1 was based on the echocardiograms close to 1-year follow-up.

Conventional 2-dimensional, pulsed, continuous-wave, and color Doppler images were acquired in parasternal and apical views, digitally stored, and analyzed offline using EchoPAC (version 112, 202, and 203; GE Medical Systems, Horten, Norway). LV and left atrial (LA) dimensions were assessed in the parasternal long-axis view. Apical 2- and 4chamber views were used to measure LA volume, LV end-diastolic, and LV end-systolic volumes. The Simpson's biplane method was used to calculate LV ejection fraction (LVEF).$^{10}$ All volumes were indexed for body surface area. Continuous-wave Doppler imaging was used to obtain mean pressure gradient across the MV. MR was graded according to current guidelines using a multiparametric approach. ${ }^{11}$

\section{Advanced Echocardiography: Speckle-Tracking Imaging}

The assessment of LV GLS was performed by speckle-tracking analysis. Apical 4-, 2-, and 3-chamber views were used to trace the LV endocardial border at end-systole. The software (EchoPAC version 112, 202 and 203 GE Medical Systems) provides LV GLS as the average value of peak systolic longitudinal strain across all 3 apical views using a 17- 
TABLE 1. Echocardiographic parameters from preoperative to immediately postoperative and late follow-up after mitral valve repair in the overall population

\begin{tabular}{|c|c|c|c|}
\hline \multicolumn{4}{|c|}{ Resect group $(\mathbf{n}=\mathbf{8 2})$} \\
\hline & Baseline & Immediately postoperative & Late follow-up \\
\hline LA end-diastolic diameter, $\mathrm{mm}$ & $44 \pm 7$ & $39 \pm 7 *$ & $37 \pm 8^{*}, \dagger$ \\
\hline LA volume index, $\mathrm{mL} / \mathrm{m}^{2}$ & $57 \pm 27$ & $40 \pm 20^{*}$ & $34 \pm 16^{*}, \dagger$ \\
\hline LV end-diastolic diameter, $\mathrm{mm}$ & $54 \pm 6$ & $50 \pm 6^{*}$ & $49 \pm 8^{*}$ \\
\hline LV end-systolic diameter, $\mathrm{mm}$ & $32 \pm 6$ & $34 \pm 7 *$ & $32 \pm 7$ \\
\hline $\mathrm{LV}$ end-diastolic volume index, $\mathrm{mL} / \mathrm{m}^{2}$ & $69 \pm 17$ & $55 \pm 12^{*}$ & $53 \pm 15^{*}$ \\
\hline $\mathrm{LV}$ end-systolic volume index, $\mathrm{mL} / \mathrm{m}^{2}$ & $24 \pm 9$ & $26 \pm 9$ & $23 \pm 11 \dagger$ \\
\hline LVEF, \% & $65 \pm 8$ & $53 \pm 8^{*}$ & $57 \pm 9^{*}, \dagger$ \\
\hline LV GLS, \% & $21.2 \pm 3.2$ & $13.6 \pm 3.3^{*}$ & $15.8 \pm 3.5^{*}, \dagger$ \\
\hline Corrected LV GLS, \%/10 mL & $1.76 \pm 0.58$ & $1.39 \pm 0.49^{*}$ & $1.71 \pm 0.56 \dagger$ \\
\hline MV mean gradient, $\mathrm{mm} \mathrm{Hg}$ & $2.9 \pm 1.5$ & $3.4 \pm 1.6^{*}$ & $2.9 \pm 1.1 \dagger$ \\
\hline MR grade $>2, n(\%)$ & $82(100)$ & $0(0)^{*}$ & $2(2)^{*}$ \\
\hline \multicolumn{4}{|c|}{ Respect group $(n=43)$} \\
\hline & Baseline & Immediately postoperative & Late follow-up \\
\hline LA end-diastolic diameter, $\mathrm{mm}$ & $45 \pm 7$ & $38 \pm 7^{*}$ & $37 \pm 6^{*}$ \\
\hline LA volume index, $\mathrm{mL} / \mathrm{m}^{2}$ & $49 \pm 16$ & $40 \pm 15^{*}$ & $32 \pm 12^{*}, \dagger$ \\
\hline LV end-diastolic diameter, mm & $56 \pm 6$ & $51 \pm 8^{*}$ & $51 \pm 6^{*}$ \\
\hline LV end-systolic diameter, mm & $34 \pm 6$ & $37 \pm 7$ & $33 \pm 7 \dagger$ \\
\hline $\mathrm{LV}$ end-diastolic volume index, $\mathrm{mL} / \mathrm{m}^{2}$ & $69 \pm 17$ & $58 \pm 13^{*}$ & $55 \pm 13^{*}$ \\
\hline $\mathrm{LV}$ end-systolic volume index, $\mathrm{mL} / \mathrm{m}^{2}$ & $26 \pm 7$ & $27 \pm 8$ & $23 \pm 9^{*}, \dagger$ \\
\hline LVEF, \% & $63 \pm 6$ & $53 \pm 8^{*}$ & $58 \pm 7 *, \dagger$ \\
\hline LV GLS, $\%$ & $20.9 \pm 3.0$ & $13.6 \pm 3.1 *$ & $16.8 \pm 2.9^{*}, \dagger$ \\
\hline Corrected LV GLS, $\% / 10 \mathrm{~mL}$ & $1.70 \pm 0.57$ & $1.30 \pm 0.45^{*}$ & $1.70 \pm 0.54 \dagger$ \\
\hline MV mean gradient, $\mathrm{mm} \mathrm{Hg}$ & $2.7 \pm 1.4$ & $3.1 \pm 1.0$ & $2.8 \pm 1.5$ \\
\hline MR grade $>2, n(\%)$ & $43(100)$ & $0(0)^{*}$ & $2(5)^{*}$ \\
\hline
\end{tabular}

$L A$, Left atrial; $L V$, left ventricular; $E F$, ejection fraction; $G L S$, global longitudinal strain; $M V$, mitral valve; $M R$, mitral regurgitation. $* P<.05$ versus baseline. $\dagger P<.05$ versus postoperative.

segment model. LV GLS reflecting myocardial shortening during systole is presented as a negative value by the software (less negative values indicate worse systolic function, less shortening). However, in this study, LV GLS is reported in absolute values to help interpretation. In addition, as previously suggested, ${ }^{12}$ LV GLS was corrected for LV end-diastolic volume and presented as percentage of deformation per $10 \mathrm{~mL}$ of $\mathrm{LV}$ volume. This correction was performed to adequately assess the myocardial contractility in the presence of significant changes in LV volumes over time (as is expected after MV repair) (Figure 1).

\section{Statistical Analysis}

Nominal variables are expressed as absolute frequencies and percentages. Continuous variables are presented as mean \pm standard deviation, when normally distributed and as median with interquartile range (IQR) when not normally distributed. The Kolmogorov-Smirnov test and the Shapiro-Wilk test were used to assess for normality. The chi-square test, unpaired Student $t$ test, Mann-Whitney $U$ test, 1-way analysis of variance, and Kruskal-Wallis test were used for the analysis of clinical, surgical, and echocardiographic variables and outcome events as appropriate. Multiple pairwise comparisons within groups were performed with the paired Student $t$ test. Mixed model regression was performed for all the LV function parameters (LVEF, LV GLS, and corrected LV GLS), adjusting for withinpatient correlation in observed outcomes. The analysis was started by first estimating mixed models with a linear trend before surgery, fitting an additional linear trend across time from surgery date onward to accommodate for potential differential time effect from surgery, as well as treatment indicator for surgery effect (again defined from surgery onwards) and a timeby treatment interaction effect (to accommodate for potential differential postsurgery time trends between treatment groups). We then assessed the interaction effects first. Upon nonsignificance of the interaction terms, models were refitted without the interaction, leaving only the main effects, and the treatment effects were reported from the thus defined final models. We assessed model fit using residuals derived from the model. Effects, standard errors, confidence intervals, and $P$ values are reported from the estimated models. Kaplan-Meier analysis was performed to assess the difference in outcome (all-cause mortality, recurrence of MR, and MV reintervention) between the 2 groups (log-rank test). Statistical analysis was performed using SPSS version 23.0 (IBM Corp, Armonk, NY).

\section{RESULTS}

\section{Baseline Clinical and Echocardiographic Characteristics}

After the exclusion criteria, 125 patients were included in this study; 82 patients $(66 \%)$ underwent leaflet resection (resect group), and 43 patients (34\%) underwent isolated 


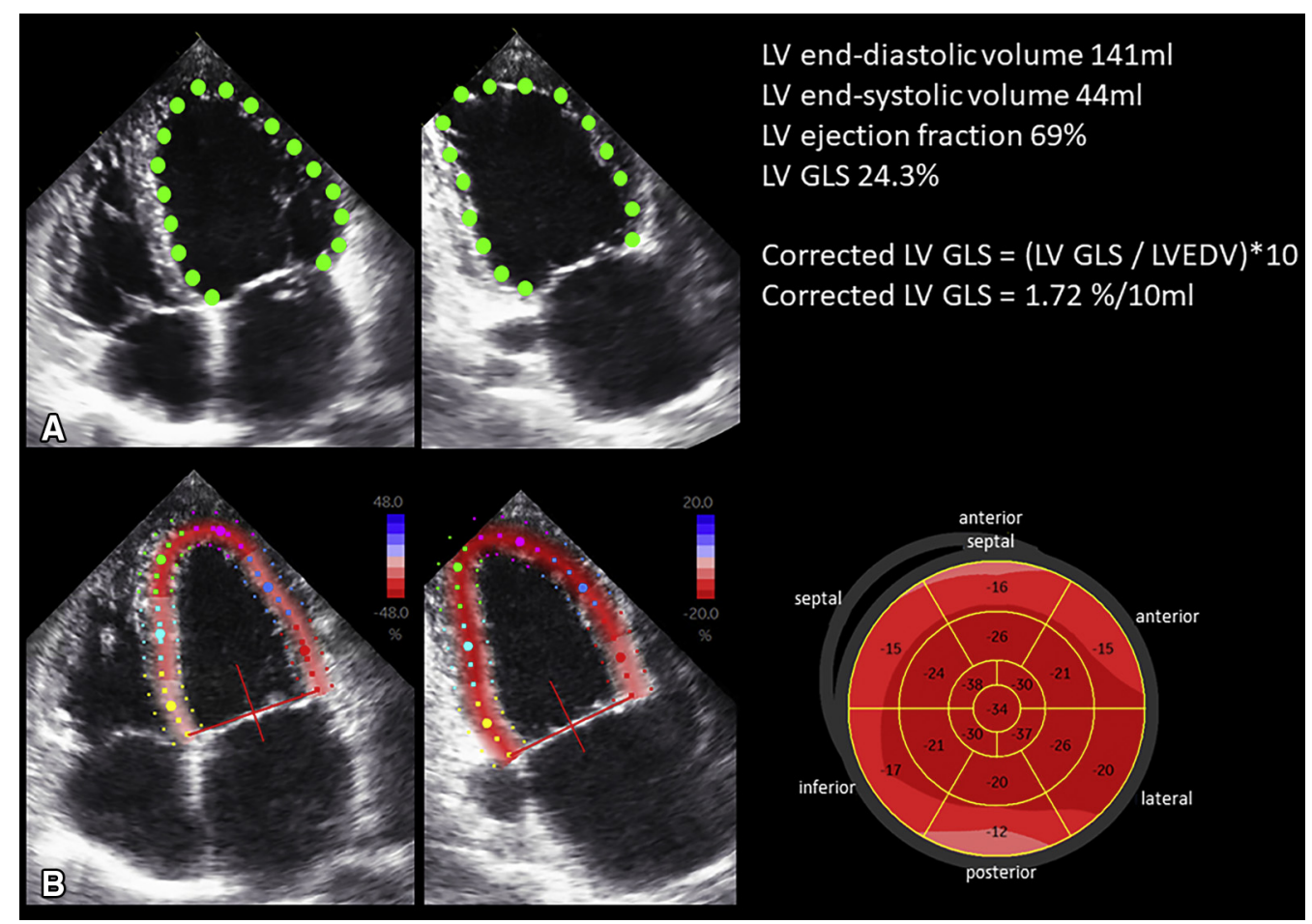

FIGURE 1. Echocardiographic example of corrected LV GLS. Example of corrected LV GLS assessment by 2-dimensional speckle-tracking analysis in a patient with severe MR. A, The LV end-diastolic volume in the apical 4- and 2-chamber views, which is $141 \mathrm{~mL}$ in this example. The LV end-systolic volume was $44 \mathrm{~mL}$ (calculation not shown), which resulted in a LVEF of $69 \%$. B. The region of interest in the corresponding 2 views for the calculation of LV GLS and the bulls-eye (right lower panel) with the strain values for all the segments based on 3 views (apical 4-, 2-, and 3-chamber views): LV GLS is then calculated as the average of peak longitudinal strain of all segments, which in this example is $24.3 \%$. The corrected LV GLS in this example was $1.72 \% / 10 \mathrm{~mL}$. $L V$, Left ventricular; $G L S$, global longitudinal strain; $L V E D V$, left ventricular end-diastolic volume.

chordal replacement (respect group). The mean age of the total population was $63 \pm 12$ years, and the majority of patients were male $(64 \%)$. Patients in the resect group were similar to patients in the respect group in terms of age, symptoms, comorbidities, renal function, European System for Cardiac Operative Risk Evaluation II, and medication use (Table 2).

When assessing the echocardiographic parameters at baseline ( 2 months; IQR, 0-5 months before surgery) in the overall population, LVEF was $64 \% \pm 8 \%$ and the corrected LV GLS was $1.74 \% \pm 0.57 \% / 10 \mathrm{~mL}$. At baseline, $\mathrm{LV}$ dimensions and volumes, $\mathrm{LV}$ function, and mean gradient across the MV did not significantly differ between the resect and respect groups. Only LA volume index was significantly larger in the resect group compared with the respect group $\left(57 \pm 27\right.$ vs $\left.49 \pm 16 \mathrm{~mL} / \mathrm{m}^{2}, P=.044\right)$ (Table 2).

\section{Surgical Data}

The intraoperative details are presented in Table 3. On evaluation of the performed repair technique, in the 82 patients in the resect group, $19(23 \%)$ underwent annular plication, $63(77 \%)$ underwent leaflet sliding, and 41
$(50 \%)$ underwent chordal replacement in addition to leaflet resection. The median implanted ring size was $34 \mathrm{~mm}$ for the overall population and did not significantly differ between the resect and respect groups $(P=.144)$. The cardiopulmonary bypass and the aortic crossclamp times were significantly longer in the resect group compared with the respect group $(182 \pm 49$ vs $147 \pm 44$ minutes, $P<.001$ and $140 \pm 41$ vs $108 \pm 35$ minutes, $P<.001$, respectively). Furthermore, the Maze procedure was more often performed in the resect group than in the respect group $(33 \%$ vs $12 \%, P=.010)$.

\section{Postoperative and Late Follow-up Standard Echocardiographic Parameters}

On average, the early postoperative echocardiogram was performed at 5 days (IQR, 4-6 days) and the late follow-up echocardiogram at 13 months (IQR, 7.5-18 months) after surgery. After MV repair, significant changes in LA and LV dimensions and volumes, as well as significant changes in the LV function, were observed over time in both groups when assessed with LVEF (Table 1).

Compared with baseline, LV end-diastolic volume index decreased significantly postoperatively in both groups 
TABLE 2. Baseline clinical and echocardiographic characteristics

\begin{tabular}{|c|c|c|c|c|c|}
\hline & \multicolumn{2}{|c|}{$\begin{array}{c}\text { Total population } \\
\quad \mathbf{N}=125 \\
\end{array}$} & $\begin{array}{c}\text { Resect group } \\
\quad \mathbf{N}=\mathbf{8 2}\end{array}$ & $\begin{array}{l}\text { Respect group } \\
\quad \mathbf{N}=43\end{array}$ & $P$ value \\
\hline \multicolumn{6}{|l|}{ Clinical characteristics } \\
\hline Age, y & $\mathrm{n}=125$ & $63 \pm 12$ & $63 \pm 12$ & $62 \pm 12$ & .519 \\
\hline Male, n (\%) & $\mathrm{n}=125$ & $80(64)$ & $47(57)$ & $33(77)$ & .032 \\
\hline $\mathrm{NYHA} \geq \mathrm{II}, \mathrm{n}(\%)$ & $\mathrm{n}=125$ & $94(75)$ & $63(77)$ & $31(72)$ & .588 \\
\hline History of AF, n (\%) & $\mathrm{n}=125$ & $37(30)$ & $28(34)$ & $9(21)$ & .124 \\
\hline Hypertension, n (\%) & $\mathrm{n}=125$ & $41(33)$ & $28(34)$ & $13(30)$ & .658 \\
\hline Diabetes, n $(\%)$ & $\mathrm{n}=125$ & $3(2)$ & $2(2)$ & $1(2)$ & .969 \\
\hline Chronic lung disease, $\mathrm{n}(\%)$ & $\mathrm{n}=124$ & $8(6)$ & $5(6)$ & $3(7)$ & .862 \\
\hline Coronary artery disease, $\mathrm{n}(\%)$ & $\mathrm{n}=123$ & $4(3)$ & $2(2)$ & $2(5)$ & .521 \\
\hline $\mathrm{eGFR}, \mathrm{mL} / \mathrm{min} / 1.73 \mathrm{~m}^{2}$ & $\mathrm{n}=125$ & $73 \pm 16$ & $72 \pm 15$ & $76 \pm 18$ & .163 \\
\hline \multicolumn{6}{|l|}{ Medication, n (\%) } \\
\hline Beta-blocker & $\mathrm{n}=125$ & $49(39)$ & $29(35)$ & $20(47)$ & .225 \\
\hline ACE inhibitor/ARB & $\mathrm{n}=125$ & $61(49)$ & $40(49)$ & $21(49)$ & .995 \\
\hline Diuretics & $\mathrm{n}=125$ & $42(34)$ & $31(38)$ & $11(26)$ & .169 \\
\hline euroSCORE II & $\mathrm{n}=125$ & $1.76(1.03-3.09)$ & $1.71(1.00-3.31)$ & $1.81(1.03-2.89)$ & .923 \\
\hline \multicolumn{6}{|l|}{ Echocardiographic characteristics } \\
\hline LA end-diastolic diameter, $\mathrm{mm}$ & $\mathrm{n}=125$ & $44 \pm 7$ & $44 \pm 7$ & $45 \pm 7$ & .395 \\
\hline LA volume index, $\mathrm{mL} / \mathrm{m}^{2}$ & $\mathrm{n}=123$ & $54 \pm 24$ & $57 \pm 27$ & $49 \pm 16$ & .044 \\
\hline LV end-diastolic diameter, $\mathrm{mm}$ & $\mathrm{n}=125$ & $54 \pm 6$ & $54 \pm 6$ & $56 \pm 6$ & .106 \\
\hline LV end-systolic diameter, $\mathrm{mm}$ & $\mathrm{n}=125$ & $33 \pm 6$ & $32 \pm 6$ & $34 \pm 6$ & .057 \\
\hline $\mathrm{LV}$ end-diastolic volume index, $\mathrm{mL} / \mathrm{m}^{2}$ & $\mathrm{n}=125$ & $69 \pm 17$ & $69 \pm 17$ & $69 \pm 17$ & .857 \\
\hline $\mathrm{LV}$ end-systolic volume index, $\mathrm{mL} / \mathrm{m}^{2}$ & $\mathrm{n}=125$ & $25 \pm 8$ & $24 \pm 9$ & $26 \pm 7$ & .360 \\
\hline LVEF, $\%$ & $\mathrm{n}=125$ & $64 \pm 8$ & $65 \pm 8$ & $63 \pm 6$ & .295 \\
\hline LV GLS, $\%$ & $\mathrm{n}=125$ & $21.1 \pm 3.3$ & $21.2 \pm 3.2$ & $20.9 \pm 3.0$ & .634 \\
\hline Corrected LV GLS, \%/10 mL & $\mathrm{n}=125$ & $1.74 \pm 0.57$ & $1.76 \pm 0.58$ & $1.70 \pm 0.57$ & .560 \\
\hline MV mean gradient, $\mathrm{mm} \mathrm{Hg}$ & $\mathrm{n}=122$ & $2.8 \pm 1.5$ & $2.9 \pm 1.5$ & $2.7 \pm 1.4$ & .417 \\
\hline
\end{tabular}

NYHA, New York Heart Association; $A F$, atrial fibrillation; $e G F R$, estimated glomerular filtration rate; $A C E$, angiotensin-converting enzyme; $A R B$, angiotensin receptor blocker; euroSCORE, European System for Cardiac Operative Risk Evaluation; $L A$, left atrial; $L V$, left ventricular; $E F$, ejection fraction; $G L S$, global longitudinal strain; $M V$, mitral valve.

(resect: $69 \pm 17$ vs $55 \pm 12 \mathrm{~mL} / \mathrm{m}^{2}, P<.001$ and respect: $69 \pm 17$ vs $\left.58 \pm 13 \mathrm{~mL} / \mathrm{m}^{2}, P<.001\right)$. At late follow-up, no further significant reduction in LV end-diastolic volume index was observed in both groups.

Postoperative LV end-systolic volume index did not significantly differ from the baseline value. On the other hand, a significant reduction in LV end-systolic volume index was observed in both groups when postoperative and late follow-up values were compared (resect: $26 \pm 9$ vs $23 \pm 11 \mathrm{~mL} / \mathrm{m}^{2}, P<.007$ and respect: $27 \pm 8$ vs $\left.23 \pm 9 \mathrm{~mL} / \mathrm{m}^{2}, P<.005\right)$. Of note, when preoperative and late follow-up LV end-systolic volume index values were compared, a significant reduction was seen only in the respect group $(P=.043)$, although the LVEF was not significantly different between the 2 groups at late follow-up.

LVEF significantly decreased postoperatively $(P<.001$ for both groups), and at late follow-up a significant improvement $(P<.001$ for both groups) was observed but without reaching baseline values $(P<.001$ for both groups). By comparing the 2 groups postoperatively and at late follow-up at those time points, no significant differences regarding LA and LV dimensions and volumes and LVEF were observed.

\section{Changes in Left Ventricular Global Longitudinal Strain After Mitral Valve Repair}

MV repair resulted in significant changes of LV GLS for both groups over time (Table 1). In comparison with baseline, a significant decrease in LV GLS was observed postoperatively ( $P<.001$ for both groups). At late follow-up, LV GLS showed a significant increase compared with postoperatively $(P<.001$ for both groups) but remained significantly lower compared with baseline ( $P<.001$ for both groups). When LV GLS was corrected for LV end-diastolic volume, the same course was observed for both groups: a significant decline postoperatively and a significant improvement at follow-up $(P<.001$ in all cases). However, in contrast to uncorrected LV GLS, the corrected LV GLS at follow-up returned to baseline in both groups (resect: $1.76 \% \pm$ $0.58 \%$ vs $1.71 \% \pm 0.56 \% / 10 \mathrm{~mL}, P=.434$ and respect $1.70 \% \pm 0.57 \%$ vs $1.70 \% \pm 0.54 \% / 10 \mathrm{~mL}, P=.997)$ (Figure 2, A) suggesting the importance to take LV volume 
TABLE 3. Intraoperative details of the total population

\begin{tabular}{|c|c|c|c|c|c|}
\hline & Tota & $\begin{array}{l}\text { Ilation } \\
25\end{array}$ & Resect group $N=82$ & Respect group $N=43$ & $P$ value \\
\hline MV annulus intervention, $\mathrm{n}(\%)$ & $\mathrm{n}=125$ & & & & $\mathrm{n} / \mathrm{a}$ \\
\hline Leaflet resection + annulus plication & & $19(15)$ & $19(23)$ & $0(0)$ & \\
\hline Triangular resection & & $0(0)$ & $0(0)$ & $0(0)$ & \\
\hline Quadrangular resection & & $19(100)$ & $19(100)$ & $0(0)$ & \\
\hline Leaflet resection + leaflet sliding & & $63(50)$ & $63(77)$ & $0(0)$ & \\
\hline Triangular resection & & $28(44)$ & $28(44)$ & $0(0)$ & \\
\hline Quadrangular resection & & $35(56)$ & $35(56)$ & $0(0)$ & \\
\hline Chordal replacement & & $84(67)$ & $41(50)$ & $43(100)$ & \\
\hline Annuloplasty & & $124(99)$ & $82(100)$ & $42(98)$ & \\
\hline Ring size $\mathrm{MV}$, mm & $\mathrm{n}=120$ & $34(32-36)$ & $34(32-36)$ & $32(32-34)$ & .144 \\
\hline \multicolumn{6}{|l|}{ Concomitant surgery, $\mathrm{n}(\%)$} \\
\hline Maze & $\mathrm{n}=125$ & $32(26)$ & $27(33)$ & $5(12)$ & .010 \\
\hline TVP & $\mathrm{n}=125$ & $56(45)$ & $37(45)$ & $19(44)$ & .920 \\
\hline Cardiopulmonary bypass time, $\min$ & $\mathrm{n}=118$ & $170 \pm 50$ & $182 \pm 49$ & $147 \pm 44$ & $<.001$ \\
\hline Aortic crossclamp time, min & $\mathrm{n}=117$ & $128 \pm 41$ & $140 \pm 41$ & $108 \pm 35$ & $<.001$ \\
\hline
\end{tabular}

$M V$, Mitral valve; $n / a$, not applicable; $T V P$, tricuspid valve plasty.

into account. LV GLS and corrected LV GLS did not differ between the groups directly postoperatively or at late follow-up.

\section{Surgical Repair Technique and Left Ventricular Function Over Time}

To evaluate the potential effect of surgical repair technique on the changes in LV function over time, mixed model longitudinal analysis was performed including all echocardiograms performed up to 2 years after surgery. Of the 125 patients, 37 had more than 1 follow-up echocardiogram during this time period. This analysis revealed no significant effect of the surgical repair technique (resect vs respect) on the trend of LVEF (estimate $-1.383, P=.204,95 \% \mathrm{CI}$, -3.522-0.756), LV GLS (estimate $-0.981, P=.055$, 95\% CI, - 1.982-0.019), or corrected LV GLS (estimate $-0.005, P=.943,95 \%$ CI, $-0.139-0.129$ ) (Table 4).

Because some patients in the resect group underwent annular plication and others underwent leaflet sliding, a subanalysis was performed comparing 3 different groups: leaflet resection with annular plication $(n=19)$, leaflet resection with leaflet sliding $(\mathrm{n}=63)$, and isolated chordal replacement $(n=43)$. The 3 groups did not significantly differ at baseline, postoperatively, and late follow-up regarding the LV function assessed with LVEF, LV GLS, and corrected LV GLS (Table E1). Mixed model longitudinal analysis revealed no significant effect of the surgical repair technique on the trend of LVEF. Although a significant effect of the surgical repair technique on the trend of LV GLS was observed (mainly between the annular plication group vs the other 2 groups), this significant effect disappeared when the trend of corrected LV GLS was compared among the 3 groups (Figure 2, $B$ and Table E2).

\section{Follow-up Outcome}

The median clinical follow-up time after surgery was 72 months (IQR, 36-115 months) and was significantly different between the 2 groups, the resect group had a longer follow-up time compared with the respect group (resect group 96 months [IQR, 68-132] and respect group 46 months [IQR, 23-71]). However, this difference in follow-up time can be explained by the fact the neochord technique was introduced later compared with the resection technique. Between the 2 groups, there were no significant differences regarding all-cause mortality (log-rank chisquare $0.068 ; P=.794$ ), recurrence of MR (log-rank chisquare $0.726 ; P=.394$ ), and MV reintervention (log-rank chi-square $0.026 ; P=.872$ ) at follow-up (Figure E2).

\section{DISCUSSION}

The results of the present study show that leaflet resection and chordal replacement techniques have a similar impact on postoperative LV function as assessed with standard echocardiographic measurements but also using the more sensitive longitudinal strain analysis (Figure 3). With both surgical techniques, a decrease in LVEF and LV GLS was observed immediately postsurgery with a significant increase during follow-up, probably related to the postoperative changes in preload and afterload as shown by the correction of LV GLS for LV size (Video 1).

\section{Echocardiographic Assessment of Left Ventricular Function}

Most studies evaluating the effect of different surgical repair techniques on LV function have used standard echocardiographic parameters such as LVEF. ${ }^{13-15}$ However, particularly in the setting of MR, LVEF does not properly reflect myocardial function being preload and afterload 


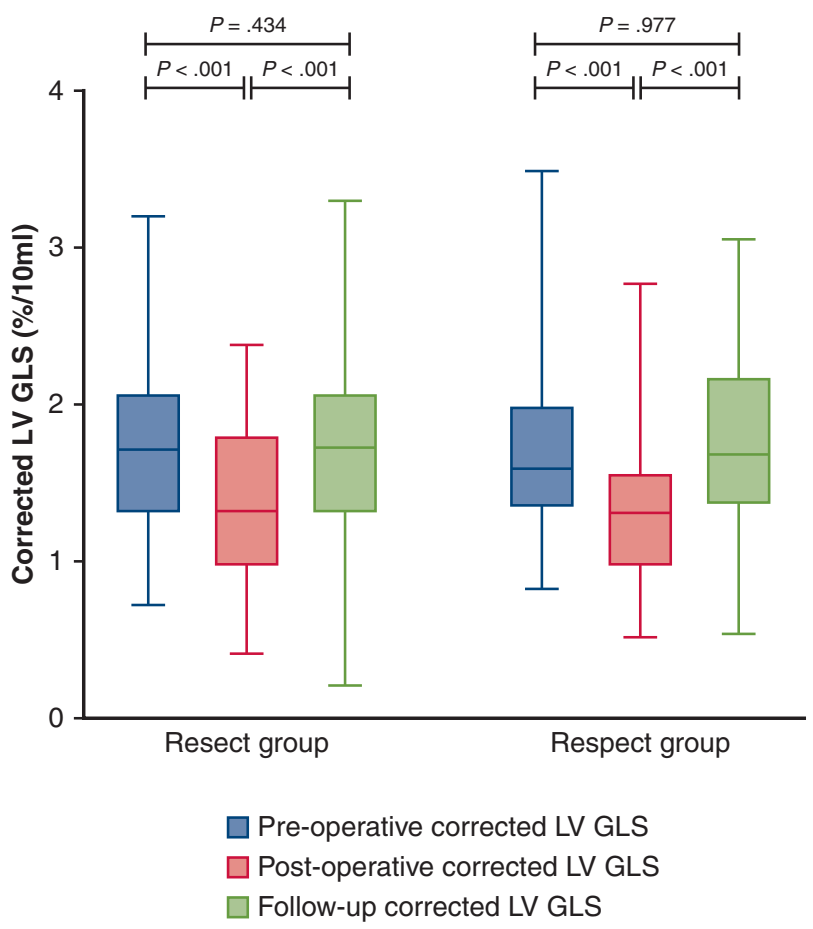

A

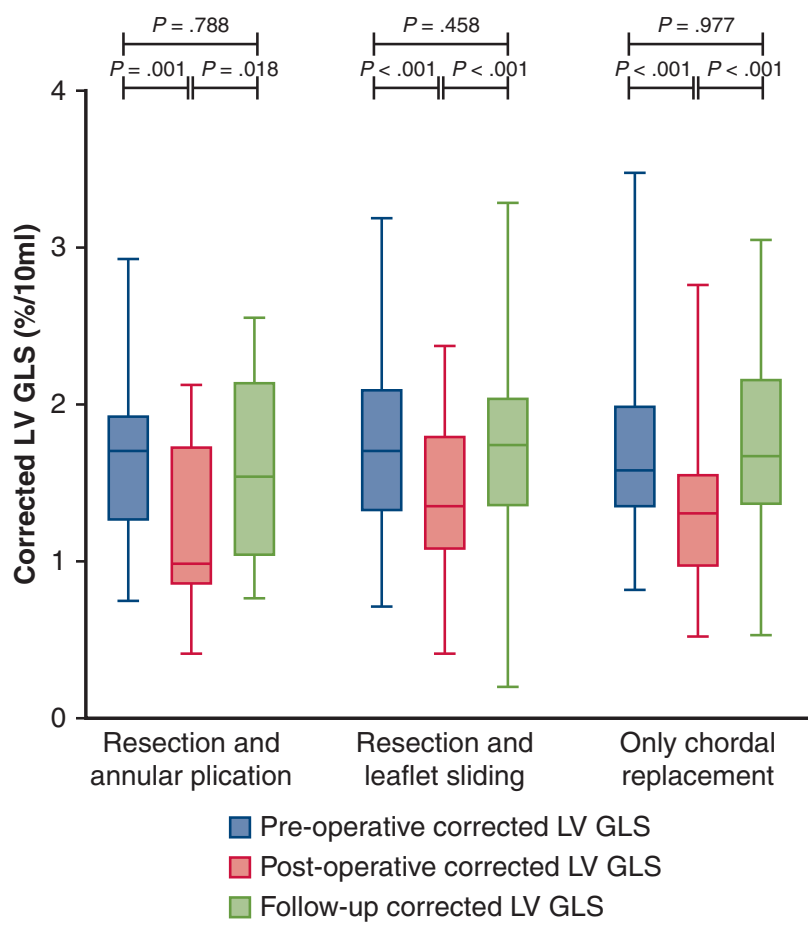

B

FIGURE 2. Sequential changes in corrected LV GLS. Sequential change in corrected LV GLS from baseline (preoperative) to immediately postoperative and late follow-up after MV repair according to resect and respect surgical repair techniques (A) and according to resection and annular plication, resection and leaflet sliding, and neochords only (B). A, Similarly for both groups, the corrected LV GLS significantly decreased after surgery but significantly improved during follow-up, back to baseline values. B, Similarly for the 3 groups, the corrected LV GLS significantly decreased after surgery but significantly improved during follow-up, back to baseline values. The whiskers represent the minimum and maximum values of nonoutliers, the confines of the box represent the first and third quartiles, and the line in the box represents the median. The $P$ values are based on the results of the paired Student $t$ test. $L V$, Left ventricular; GLS, global longitudinal strain.

dependent; in these patients, LV volumes are often enlarged while LVEF is preserved or even displays supernormal values due to reduced afterload. ${ }^{16}$ After MV repair and resolution of MR, a significant acute reduction in LV volume will occur with a relative reduction in LVEF. ${ }^{12,17,18}$ To overcome these limitations, LV GLS was proposed as novel parameter to assess LV function being more sensitive in depicting myocardial dysfunction. ${ }^{9,19}$ Nonetheless, LV GLS remains partially influenced by loading conditions; therefore, it has been suggested to correct it for LV enddiastolic volume in the setting of MR. ${ }^{12,20,21}$ In this study, although LV GLS corrected for end-diastolic volume almost

TABLE 4. Results of mixed effect longitudinal model analysis to examine the effect of the 2 different surgical repair techniques on the changes in left ventricular function

\begin{tabular}{lcccc}
\hline \multicolumn{1}{c}{ Variable } & Estimate & SE & $\boldsymbol{P}$ value & $\mathbf{9 5 \%}$ CI \\
\hline LVEF, \% & -1.383 & 1.088 & .204 & -3.522 to 0.756 \\
LV GLS, \% & -0.981 & 0.509 & .055 & -1.982 to 0.019 \\
$\begin{array}{l}\text { Corrected LV } \\
\quad \text { GLS, \%/10 mL }\end{array}$ & -0.005 & 0.068 & .943 & -0.139 to 0.129 \\
\hline
\end{tabular}

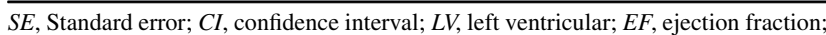
$G L S$, global longitudinal strain. returned to baseline values at late follow-up, LVEF and uncorrected LV GLS remained slightly depressed compared with baseline, reflecting the importance of adjusting the LV GLS for volume conditions.

\section{Resect Versus Respect Repair Techniques}

Posterior leaflet prolapse repair using leaflet resection with annular plication or leaflet sliding has been the preferred repair technique for many years. However, distortion of the LV morphology could present a theoretical problem of the annular plication technique, resulting from crimping of the posterior part of the MV annulus. This is supported by observations made by David and colleagues, ${ }^{22}$ who suggested that plication of more than $1.5 \mathrm{~cm}$ of the posterior annulus could have a detrimental effect on LV performance. In addition, leaflet resection in combination with annular plication or leaflet sliding may result in leaflet restriction and immobilization of the posterior leaflet. ${ }^{23}$ In our study, a negative effect of the annular plication or leaflet sliding technique on LV performance was not observed when compared with chordal replacement techniques. This is likely 


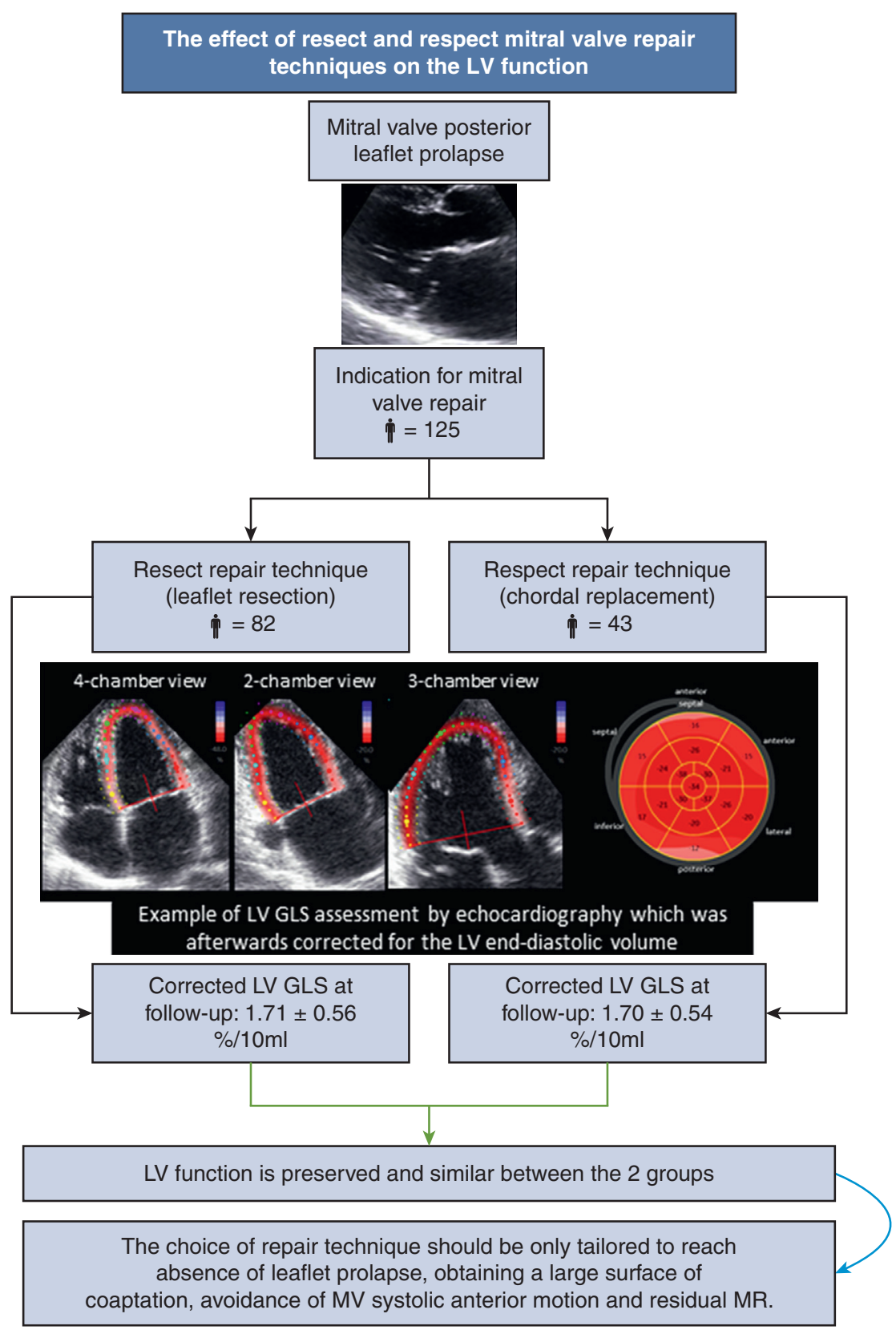

FIGURE 3. Resect and respect repair techniques are both effective at preserving LV function. The upper image shows an MV posterior leaflet prolapse. When according to current guideline criteria, indication for surgery is given, and 2 main different surgical techniques can be used to repair the valve (resect and respect). To assess the difference in LV function after surgery between these different surgical techniques, corrected LV GLS was calculated. The lower images present an example of assessing the LV GLS with 2-dimensional speckle-tracking analysis from the 4-, 3-, and 2-chamber views and the bulls-eye including the values of all segments. For the assessment of the LV function, the LV GLS was corrected for the LV end-diastolic volume to take into account the changes in volume after surgery. The corrected LV GLS did not significantly differ between the 2 groups. Both resect and respect repair techniques can be used for MV repair, and both are effective a preserving LV function assessed with GLS corrected for LV volume. $L V$, Left ventricular; $G L S$, global longitudinal strain; $M V$, mitral valve; $M R$, mitral regurgitation.

because the posterior MV annulus is fixed in the systolic configuration by prosthetic annuloplasty, used in all types of posterior leaflet repair, to secure optimal systolic leaflet apposition. Nonelasticity of the prosthetic annuloplasty devices will prevent normal diastolic lengthening of the posterior circumference of the MV annulus. It is possible that this in turn impairs LV systolic performance. It should be noted that this is unrelated to the type of leaflet repair performed and to the type of annuloplasty used (rigid, semi-rigid, or flexible) because material nonelasticity is needed to secure optimal device function. 

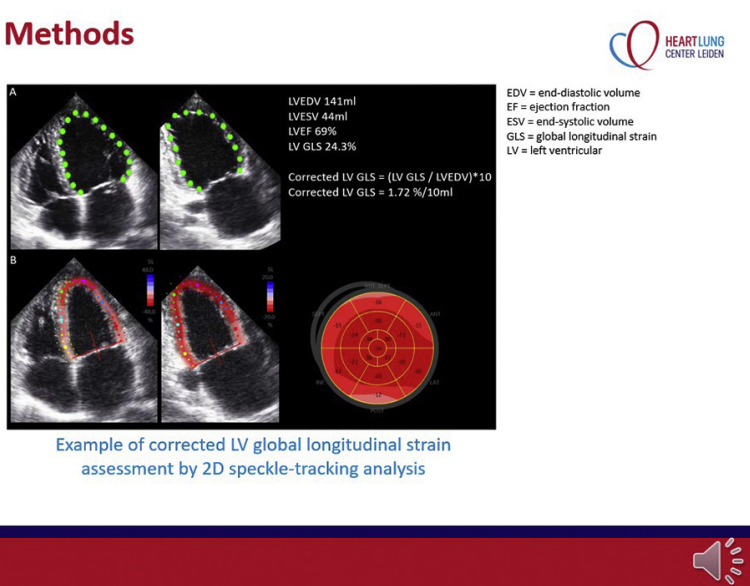

VIDEO 1. Short presentation about the impact of different surgical repair techniques for isolated posterior MV leaflet prolapse on LV function. Video available at: https://www.jtcvs.org/article/S0022-5223(21)00329-9/ fulltext.

In a recent meta-analysis on the outcomes of MV repair for posterior leaflet prolapse, Mazine and colleagues ${ }^{8}$ found that chordal replacement techniques resulted in higher postoperative LVEF than leaflet resection. Their results are largely based on the results of the study by Imasaka and colleagues, ${ }^{15}$ who compared the hemodynamic performance of the LV before and 1 month after valve repair in 72 patients who underwent MV repair with chordal replacement or posterior leaflet resection. One month after surgery, superior improvement of LVEF was seen in the chordal replacement group. The authors of this study speculated that superior preservation of the mitral-ventricular continuity could provide an explanation for their findings. ${ }^{15}$ However, this hypothesis has not been demonstrated, and an alternative explanation could be the bias in choosing the surgical technique based on MV characteristics, because patients with MV leaflet flail, limited leaflet degeneration, and possibly preserved secondary chordae are more likely to undergo chordal replacement than leaflet resection. Furthermore as mentioned, the use of LVEF as a parameter of LV function might limit the correct interpretation of the findings. 5,24

The current study using advanced echocardiographic measures did not support the superiority of the chordal replacement technique on postoperative LV function and showed a similar trend in the changes of LVEF, LV GLS, and LV GLS corrected for LV end-diastolic volume over time for both surgical techniques. A postoperative decrease in LV performance was seen early after surgery, most likely due to the sudden changes in preload and afterload (and volume shifts) after surgery, considering that at late follow-up a recovery in LV performance was observed in all groups when using corrected LV GLS (values returned to baseline). Postoperative stunning could play an additional role in the immediate postsurgery assessment and changes in LV function after operation might also be influenced by the $\mathrm{LV}$ function before operation, if a patient is referred to surgery at a late stage when LV irreversible damage has occurred; although this might account for differences among individual patients, when comparing the different surgical techniques, no differences were observed in baseline LV dimensions and LV function between the resect and respect groups.

Another finding of our study was that LA volume index was significantly larger in the resect group compared with the respect group, as was the rate of concomitant Maze, which might also be explained by the fact that patients in the respect group tended to undergo operation at an earlier stage before the occurrence of severe atrial dilatation or atrial fibrillation. Finally, no differences between the groups were observed during follow-up in terms of recurrent MR, which is an important parameter influencing LV function and patient survival. ${ }^{25}$ In this regard, early results of MV repair with chordal replacement techniques have thus far been satisfactory. However, long-term results of MV repair with the sole use of chordal replacement techniques in case of posterior leaflet prolapse are lacking. In turn, posterior leaflet repair with leaflet resection has proven long-term outcomes. Lapenna and colleagues ${ }^{26}$ showed that quadrangular resection with annular plication for posterior leaflet prolapse provides excellent results up to 19 years after surgery with only a negligible amount of patients experiencing recurrent MR or MV reintervention.

In our practice, the choice of MV repair technique is adapted to the extent of leaflet prolapse and excessive leaflet tissue, as previously described. ${ }^{5,7}$ We believe that leaflet resection and chordal replacement techniques are complementary in nature and provide the surgeon a toolbox of repair techniques with a common goal of achieving a stable and durable result of MV repair. The results of the current study suggest that leaflet resection does not hamper postoperative LV performance and provide an additional argument for patienttailored rather than one-size-fits-all approach to MV repair.

\section{Study Limitations}

There are several limitations of our retrospective study. First, because chordal replacement techniques are more recently introduced, this might have biased our results because of the experience of the surgeon with the technique and changing patient profiles over time. Second, our cohort had few events in terms of outcomes (all-cause mortality, reoccurrence of significant MR, and redo MV surgery); therefore, a robust conclusion about the outcomes cannot be drawn. In addition, the follow-up time for the resection group is longer than for the respect group, because the latter was more recently introduced. Third, by applying specific exclusion criteria, a small chance of a selection bias is present; however, by using this selection strategy, we believe we could provide robust results (excluding important 
confounding factors) on the changes of LV function after surgery. Fourth, only GLS data were available, and regional longitudinal strain was not included for limited reproducibility of the measures. Finally, further data would be needed to confirm that both surgical techniques have the same impact on LV function.

\section{CONCLUSIONS}

Both leaflet resection and chordal replacement were effective at preserving postoperative $\mathrm{LV}$ function in patients with a posterior MV leaflet prolapse and significant MR. Therefore, the choice of repair technique should be only tailored to reach absence of leaflet prolapse, obtaining a large surface of coaptation, avoidance of MV systolic anterior motion, and residual MR.

\section{Conflict of Interest Statement}

The Department of Cardiology received unrestricted research grants from Abbott Vascular, Bayer, Bioventrix, Biotronik, Boston Scientific, Edwards Lifesciences, GE Healthcare, and Medtronic. V.D. received speaker fees from Abbott Vascular, Edwards Lifesciences, GE Healthcare, and Medtronic. N.A.M. received speakers fees from Abbott Vascular and GE Healthcare. J.J.B. received speaker fees from Abbott Vascular. All other authors reported no conflicts of interest.

The Journal policy requires editors and reviewers to disclose conflicts of interest and to decline handling or reviewing manuscripts for which they may have a conflict of interest. The editors and reviewers of this article have no conflicts of interest.

\section{References}

1. Carpentier A. Cardiac valve surgery - the "French correction". J Thorac Cardiovasc Surg. 1983;86:323-37.

2. Perier P, Hohenberger W, Lakew F, Diegeler A. Prolapse of the posterior leaflet: resect or respect. Ann Cardiothorac Surg. 2015;4:273-7.

3. David TE. Replacement of chordae tendineae with expanded polytetrafluoroethylene sutures. J Card Surg. 1989;4:286-90.

4. Perier P, Hohenberger W, Lakew F, Batz G, Urbanski P, Zacher M, et al. Toward a new paradigm for the reconstruction of posterior leaflet prolapse: midterm results of the "respect rather than resect" approach. Ann Thorac Surg. 2008;86:718-25.

5. Tomšič A, Klautz RJM, Palmen M. Respect versus resect: two different repair techniques or two different tools in the toolbox? J Thorac Cardiovasc Surg. 2018;155:600-1.

6. Dreyfus GD, Dulguerov F, Marcacci C, Haley SR, Gkouma A, Dommerc C, et al. "Respect when you can, resect when you should": a realistic approach to posterior leaflet mitral valve repair. J Thorac Cardiovasc Surg. 2018;156:1856-66.e3.

7. Tomsic A, Hiemstra YL, van Brakel TJ, Versteegh MI, Ajmone Marsan N, Klautz RJ, et al. Excessive leaflet tissue in mitral valve repair for isolated posterior leaflet prolapse-leaflet resection or shortening neochords? A propensity score adjusted comparison. J Cardiovasc Surg (Torino). 2019;60:111-8.

8. Mazine A, Friedrich JO, Nedadur R, Verma S, Ouzounian M, Juni P, et al. Systematic review and meta-analysis of chordal replacement versus leaflet resection for posterior mitral leaflet prolapse. J Thorac Cardiovasc Surg. 2018;155:120-8.
9. Hiemstra YL, Tomsic A, van Wijngaarden SE, Palmen M, Klautz RJM, Bax JJ, et al. Prognostic value of global longitudinal strain and etiology after surgery for primary mitral regurgitation. JACC Cardiovasc Imaging. 2020;13:577-85.

10. Lang RM, Badano LP, Mor-Avi V, Afilalo J, Armstrong A, Ernande L, et al Recommendations for cardiac chamber quantification by echocardiography in adults: an update from the American Society of Echocardiography and the European Association of Cardiovascular Imaging. J Am Soc Echocardiogr. 2015;28:1-39.

11. Lancellotti P, Tribouilloy C, Hagendorff A, Popescu BA, Edvardsen T, Pierard LA, et al. Recommendations for the echocardiographic assessment of native valvular regurgitation: an executive summary from the European Association of Cardiovascular Imaging. Eur Heart J Cardiovasc Imaging. 2013;14: 611-44.

12. Marciniak A, Claus P, Sutherland GR, Marciniak M, Karu T, Baltabaeva A, et al. Changes in systolic left ventricular function in isolated mitral regurgitation. A strain rate imaging study. Eur Heart J. 2007;28:2627-36.

13. Falk V, Seeburger J, Czesla M, Borger MA, Willige J, Kuntze T, et al. How does the use of polytetrafluoroethylene neochordae for posterior mitral valve prolapse (loop technique) compare with leaflet resection? A prospective randomized trial. J Thorac Cardiovasc Surg. 2008;136:1200-6.

14. Seeburger J, Falk V, Borger MA, Passage J, Walther T, Doll N, et al. Chordae replacement versus resection for repair of isolated posterior mitral leaflet prolapse: a egalite. Ann Thorac Surg. 2009;87:1715-20.

15. Imasaka K, Tayama E, Tomita Y. Left ventricular performance early after repai for posterior mitral leaflet prolapse: chordal replacement versus leaflet resection. J Thorac Cardiovasc Surg. 2015;150:538-45.

16. Nishimura RA, Otto CM, Bonow RO, Carabello BA, Erwin JP III, Fleisher LA, et al. 2017 AHA/ACC focused update of the 2014 AHA/ACC guideline for the management of patients with valvular heart disease: a report of the American College of Cardiology/American Heart Association task force on clinical practice guidelines. J Am Coll Cardiol. 2017;70:252-89.

17. Ahmed MI, Gladden JD, Litovsky SH, Lloyd SG, Gupta H, Inusah S, et al Increased oxidative stress and cardiomyocyte myofibrillar degeneration in patients with chronic isolated mitral regurgitation and ejection fraction $>60 \%$.J Am Call Cardiol. 2010;55:671-9.

18. Witkowski TG, Thomas JD, Debonnaire PJ, Delgado V, Hoke U, Ewe SH, et al Global longitudinal strain predicts left ventricular dysfunction after mitral valve repair. Eur Heart J Cardiovasc Imaging. 2013;14:69-76.

19. D'Hooge J, Heimdal A, Jamal F, Kukulski T, Bijnens B, Rademakers F, et al Regional strain and strain rate measurements by cardiac ultrasound: principles, implementation and limitations. Eur J Echocardiogr. 2000;1:154-70.

20. Choi JO, Shin DH, Cho SW, Song YB, Kim JH, Kim YG, et al. Effect of preload on left ventricular longitudinal strain by 2D speckle tracking. Echocardiography. 2008;258:873-9.

21. Witkowski TG, Thomas JD, Delgado V, van Rijnsoever E, Ng ACT, Hoke U, et al. Changes in left ventricular function after mitral valve repair for severe organic mitral regurgitation. Ann Thorac Surg. 2012;93:754-60.

22. David TE, Omran A, Armstrong S, Sun Z, Ivanov J. Long-term results of mitral valve repair for myxomatous disease with and without chordal replacement with expanded polytetrafluoroethylene sutures. J Thorac Cardiovasc Surg. 1998;115: 1279-85.

23. Dreyfus GD, Corbi P, Rubin S, Aubert S. Posterior leaflet preservation in mitra valve prolapse: a new approach to mitral repair. J Heart Valve Dis. 2006;15: 528-30.

24. Suri RM, Enriquez-Sarano M, Schaff HV. Preservation of left ventricular function after degenerative mitral valve repair: refocusing on timing, techniques, and teaching. J Thorac Cardiovasc Surg. 2015;5150:448-9.

25. Suri RM, Clavel MA, Schaff HV, Michelena HI, Huebner M, Nishimura RA, et al. Effect of recurrent mitral regurgitation following degenerative mitral valve repair: long-term analysis of competing outcomes. J Am Coll Cardiol. 2016;67: 488-98.

26. Lapenna E, Del Forno B, Amore L, Ruggeri S, Iaci G, Schiavi D, et al. Durability at 19 years of quadrangular resection with annular plication for mitral regurgitation. Ann Thorac Surg. 2018;106:735-41.

Key Words: echocardiography, imaging, mitral valve prolapse, mitral valve repair 


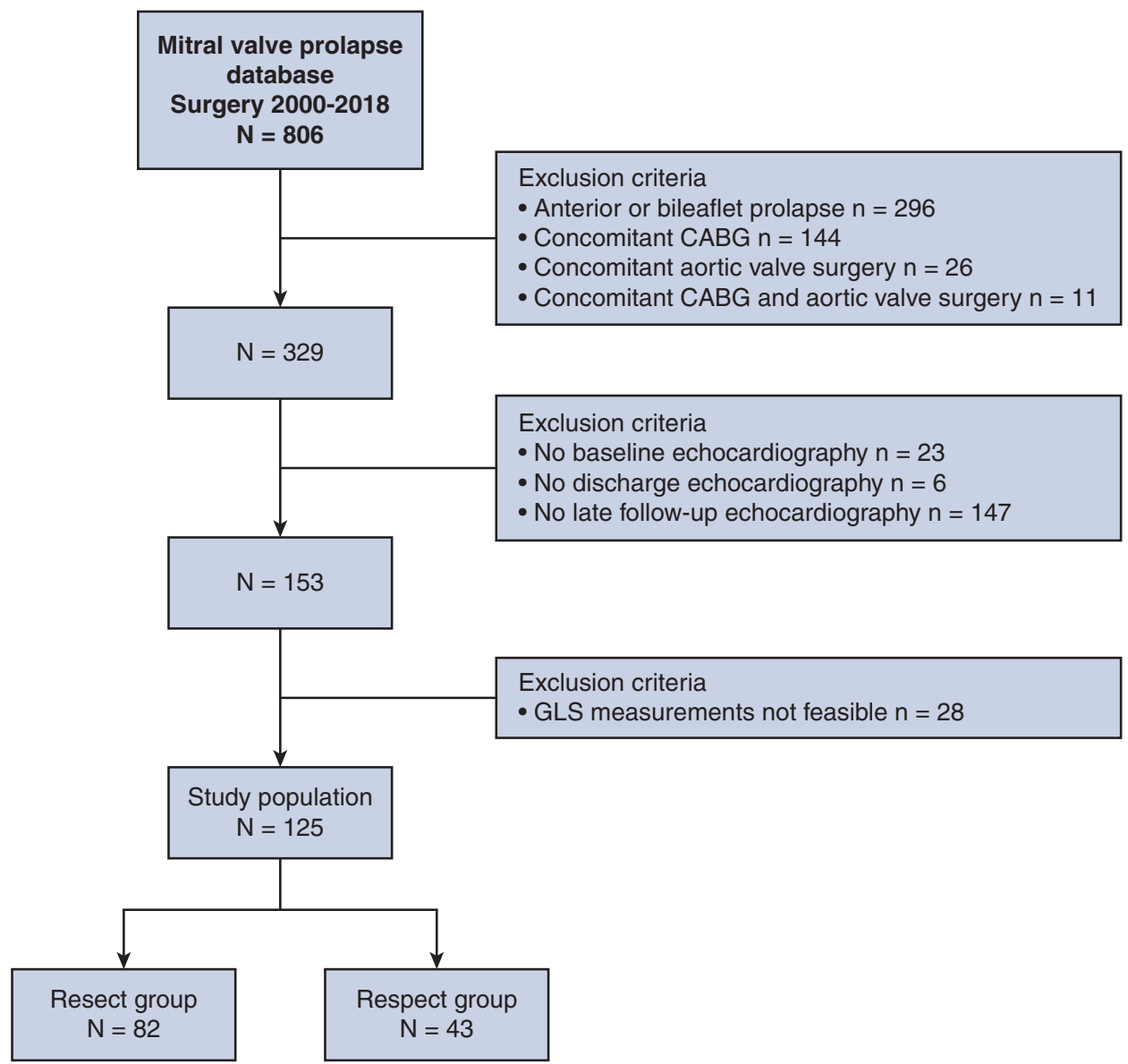

FIGURE E1. Overview of the patient population. $C A B G$, Coronary artery bypass grafting; $G L S$, global longitudinal strain. 


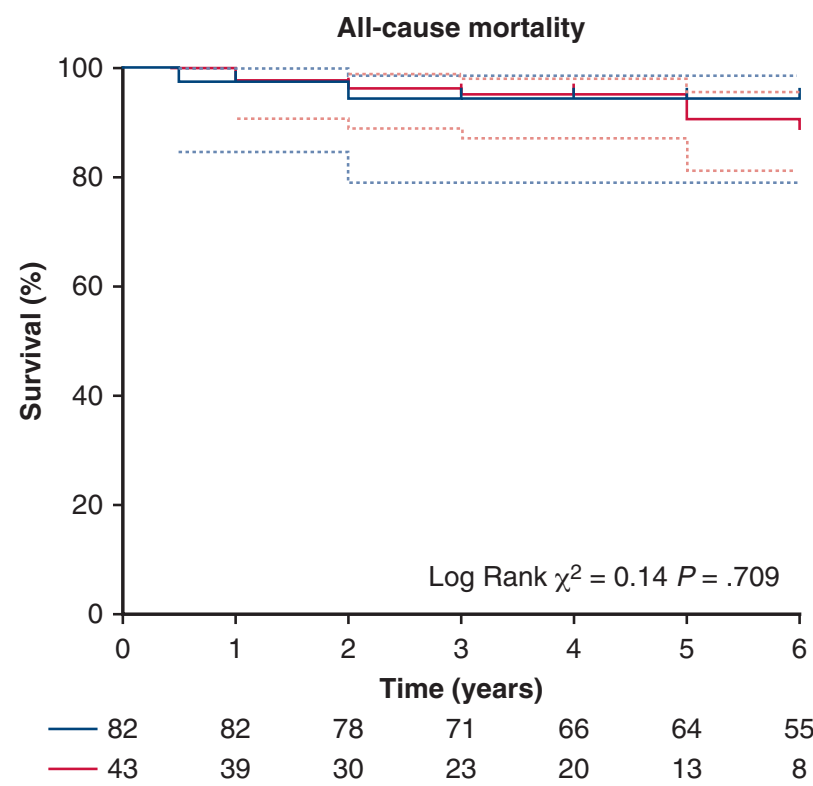

A

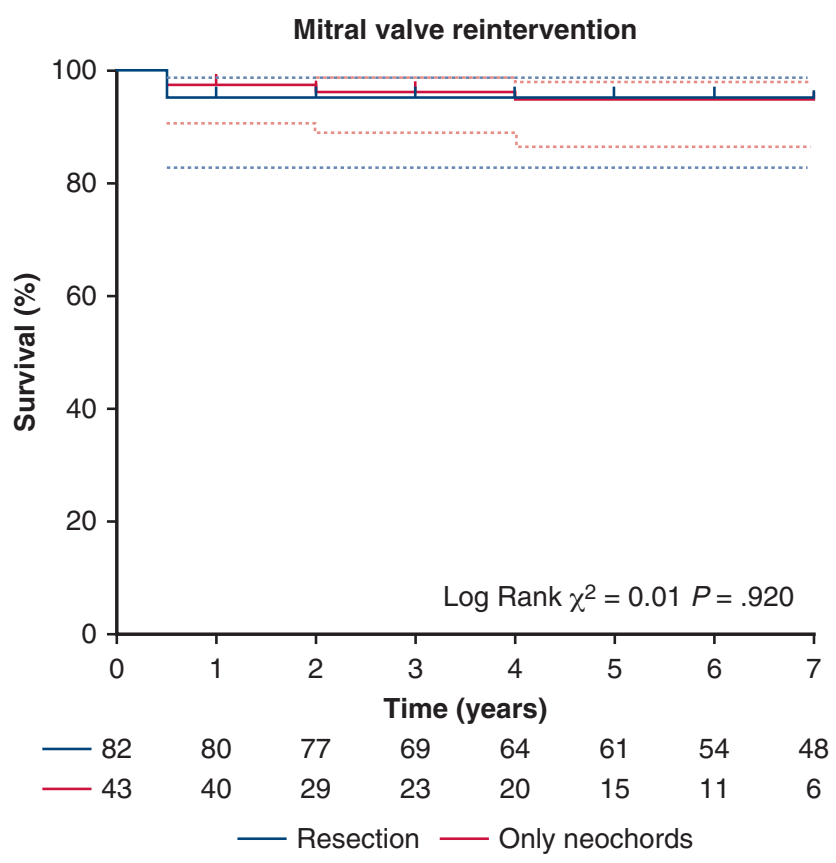

B

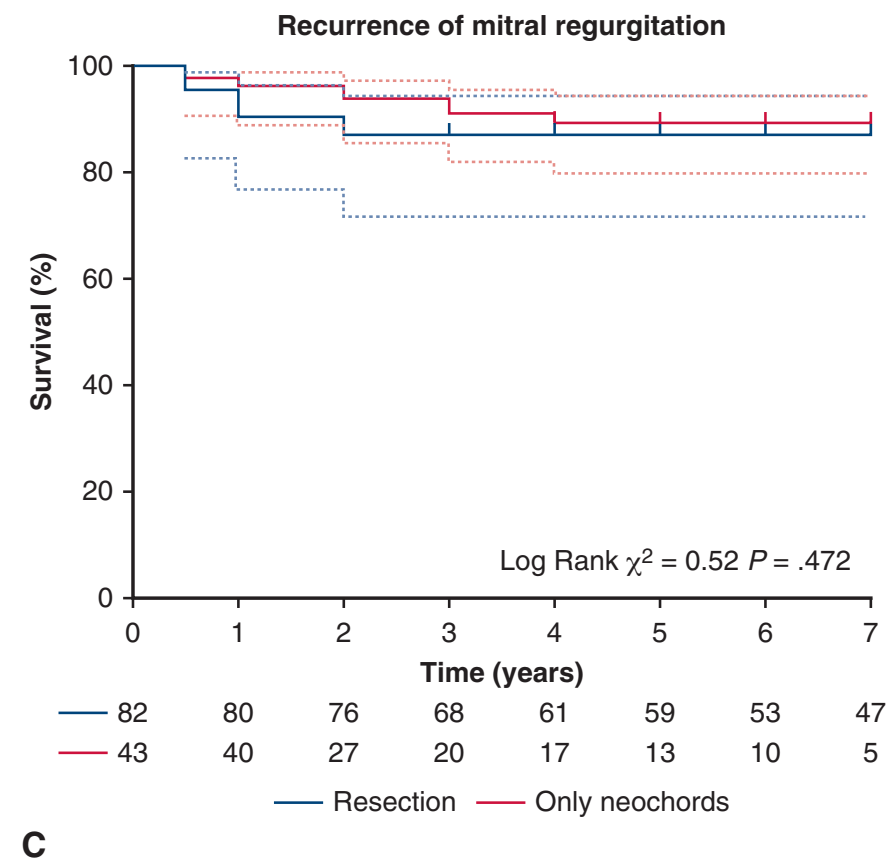

FIGURE E2. Kaplan-Meier curves for all-cause mortality, recurrence of significant MR, and MV reintervention. Kaplan-Meier curves estimated for cumulative event rates of all-cause mortality (A), recurrence of MR grade 3 or 4 (B), and MV reintervention (C). The table below the curves shows the number of patients at risk, and the dotted lines represent the $95 \%$ confidence interval. 
TABLE E1. Changes over time in left ventricular function after mitral valve repair: Direct comparison between resection and annular plication, resection and leaflet sliding, and isolated chordal replacement

\begin{tabular}{|c|c|c|c|}
\hline & Baseline & Immediately postoperative & Late follow-up \\
\hline \multicolumn{4}{|l|}{ LVEF, \% } \\
\hline Resection and annular plication & $67 \pm 6$ & $54 \pm 9$ & $56 \pm 10$ \\
\hline Resection and leaflet sliding & $64 \pm 9$ & $53 \pm 8$ & $58 \pm 8$ \\
\hline Isolated chordal replacement & $63 \pm 6$ & $53 \pm 8$ & $58 \pm 7$ \\
\hline$P$ value & 0.312 & 0.471 & 0.805 \\
\hline \multicolumn{4}{|l|}{ LV GLS, \% } \\
\hline Resection and annular plication & $-21.6 \pm 2.8$ & $-13.3 \pm 3.3$ & $-14.9 \pm 3.7$ \\
\hline Resection and leaflet sliding & $-21.1 \pm 3.4$ & $-13.7 \pm 3.3$ & $-16.1 \pm 3.4$ \\
\hline Isolated chordal replacement & $-20.9 \pm 3.0$ & $-13.6 \pm 3.1$ & $-16.8 \pm 2.9$ \\
\hline$P$ value & .752 & .130 & .891 \\
\hline \multicolumn{4}{|l|}{ Corrected LV GLS, $\% / 10 \mathrm{~mL}$} \\
\hline Resection and annular plication & $1.64 \pm 0.54$ & $1.25 \pm 0.51$ & $1.60 \pm 0.55$ \\
\hline Resection and leaflet sliding & $1.80 \pm 0.59$ & $1.44 \pm 0.48$ & $1.74 \pm 0.56$ \\
\hline Isolated chordal replacement & $1.70 \pm 0.57$ & $1.30 \pm 0.45$ & $1.70 \pm 0.54$ \\
\hline$P$ value & .498 & .625 & .198 \\
\hline
\end{tabular}

$L V$, Left ventricular; $E F$, ejection fraction; $G L S$, global longitudinal strain.

TABLE E2. Results of mixed effect longitudinal model to examine the effect of the 3 different surgical repair techniques on the changes in left ventricular function

\begin{tabular}{|c|c|c|c|c|c|}
\hline \multirow[b]{2}{*}{ Variable } & \multirow[b]{2}{*}{ Estimate } & \multirow[b]{2}{*}{ SE } & \multirow[b]{2}{*}{$P$ value } & \multicolumn{2}{|c|}{$95 \%$ CI } \\
\hline & & & & Lower & Upper \\
\hline \multicolumn{6}{|l|}{ LVEF, \% } \\
\hline Annular plication vs chordal replacement & -2.630 & 1.600 & .101 & -5.776 & 0.516 \\
\hline Leaflet sliding vs chordal replacement & -1.022 & 1.142 & .372 & -3.268 & 1.225 \\
\hline Leaflet sliding vs annular plication & -1.608 & 1.517 & .290 & -4.592 & 1.376 \\
\hline \multicolumn{6}{|l|}{ LV GLS, \% } \\
\hline Annular plication vs chordal replacement & -2.216 & 0.744 & .003 & -3.680 & -0.753 \\
\hline Leaflet sliding vs chordal replacement & 0.620 & 0.531 & .244 & -1.664 & 0.424 \\
\hline Leaflet sliding vs annular plication & -1.596 & 0.705 & .024 & -2.983 & -0.210 \\
\hline \multicolumn{6}{|l|}{ Corrected LV GLS, $\% / 10 \mathrm{~mL}$} \\
\hline Annular plication vs chordal replacement & -0.092 & 0.010 & .355 & -0.288 & 0.103 \\
\hline Leaflet sliding vs chordal replacement & 0.022 & 0.071 & .762 & -0.119 & 0.162 \\
\hline Leaflet sliding vs annular plication & -0.114 & 0.095 & .230 & -0.300 & 0.072 \\
\hline
\end{tabular}

$S E$, Standard error; $C I$, confidence interval; $L V$, left ventricular; $E F$, ejection fraction; $G L S$, global longitudinal strain. 